\title{
Fall Prevention: Staying Active ${ }^{1}$
}

Sergio Romero ${ }^{2}$

A decrease in your level of physical activity, and a loss of balance and CENAFS flexibility can increase your chances of falling. Other factors that may influence your risk of falling are poor vision, lack of strength, and hazards around the home such as poor lighting and cluttered walkways.

Exercises that improve your balance, flexibility, and strength can reduce your risk for falls. On the next pages are exercises that can help you maintain or improve your balance, strength, and flexibility. Talk to your health care provider before starting any exercise program.

Before you start:

- Wear comfortable clothes that will allow you to move freely.

- If you are unsteady on your feet, have someone assist you or use a chair to help with balance. As you progress in your exercises, try to use less assistance.

- If you become dizzy, out of breath, disoriented, or have any type of

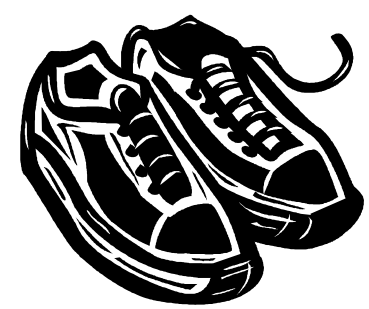
pain, especially chest pain, stop your exercises immediately. Call for help if necessary.

- Make sure to keep good posture while exercising. Keep your back straight when you are standing and concentrate on each body part you are using.

No single exercise can suit everyone. These are beginner level exercises. If you want a more challenging routine, consider these changes:

- Try not to hold onto a chair for stability; or use one hand or just one finger.

- Try to complete all repetitions on one leg before switching to the other leg.

- Increase the number of repetitions.

- Add hand or ankle weights.

1. This document is FCS2232, one in a series of the Department of Family, Youth and Community Sciences, Florida Cooperative Extension Service, Institute of Food and Agricultural Sciences, University of Florida, Gainesville, FL 32611. Publication date: November 2000. Revised: April 2005. Please visit the EDIS Website at http://edis.ifas.ufl.edu

2. Sergio Romero, MS, ATC, ENAFS education assistant, Department of Family, Youth and Community Sciences, Institute of Food and Agricultural Sciences, University of Florida, Gainesville, FL 32611. Reviewed by Leigh Ann Martin, MS and Linda B. Bobroff, PhD, RD, LD/N, Department of Family, Youth and Community Sciences, University of Florida.

The Institute of Food and Agricultural Sciences is an equal opportunity/affirmative action employer authorized to provide research, educational information and other services only to individuals and institutions that function without regard to race, color, sex, age, handicap, or national origin. For information on obtaining other extension publications, contact your county Cooperative Extension Service office. Florida Cooperative Extension Service / Institute of Food and Agricultural Sciences / University of Florida / Larry Arrington, Dean 


\section{Heel Raises}

- Stand up straight, feet flat on the floor; hold onto a chair for balance.

- Slowly raise up on tiptoes, as high as possible.

- Hold this position for about two seconds.

- Slowly lower heels to starting position.

- Repeat 8 to 15 times.

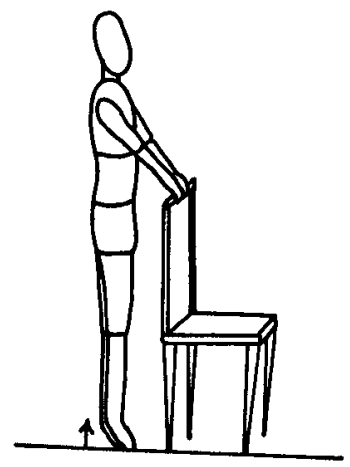

\section{Knee Flexion}

- Stand up straight; hold onto a chair for balance.

- Slowly bend knee as far as possible.

- Hold this position for about two seconds.

- Slowly lower foot back down to the floor.

- Alternate legs, repeating the exercise 8 to 15 times per leg.

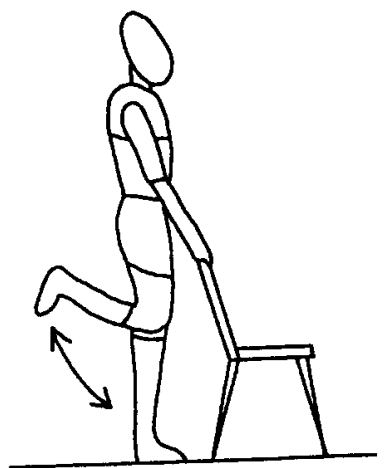

\section{Knee to Chest}

- Stand up straight, hold on to a chair or counter top for balance.

- Slowly bring one knee toward your chest, without bending at the waist or hips.

- Hold this position for about two seconds.

- Slowly lower foot back down to the floor.

- Alternate legs, repeating the exercise 8 to 15 times per leg.

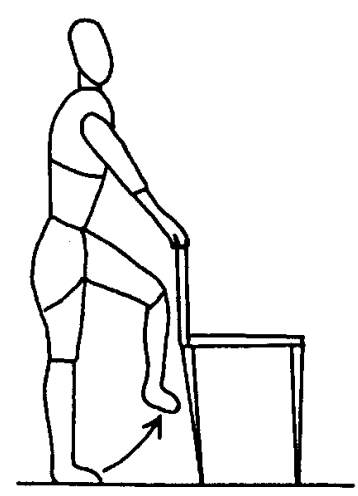

\section{Hip Extension}

- Stand 12 to 18 inches from chair.

- Slowly bring one leg straight backwards.

- Do not bend the waist.

- Hold this position for about two seconds.

- Slowly return leg to starting position. Alternate legs, repeating the exercise 8 to 15 times per leg.

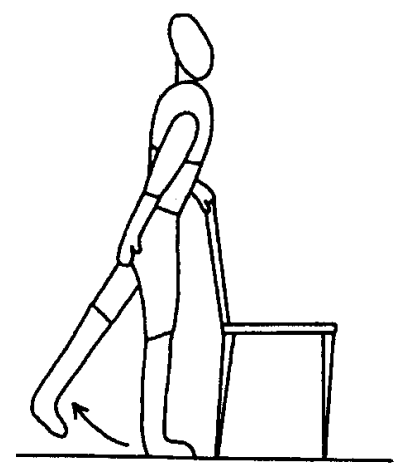




\section{Side Leg Raise}

- Stand up straight; hold onto a chair for balance.

- Slowly lift one leg to side, 8-12 inches.

- Hold position for about two seconds.

- Slowly lower leg.

- Keep back and knees straight throughout exercise.

- Alternate legs, repeating the exercise 8 to 15 times per leg.

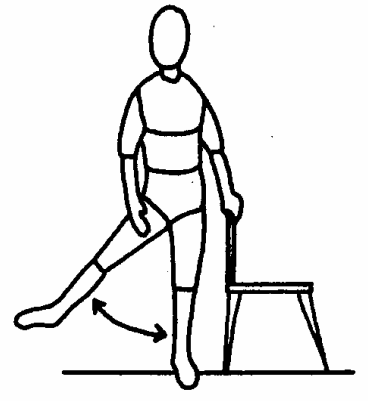

\section{Chair Squat}

- Stand up straight with a chair directly behind you.

- Use a chair with arm rests if you need more support.

- Sit down, using your legs to lower yourself down onto the chair

- Stand up slowly with little or no assistance from your arms.

- Pause after standing and sitting so you do not become dizzy.

- Repeat 8 to 15 times.

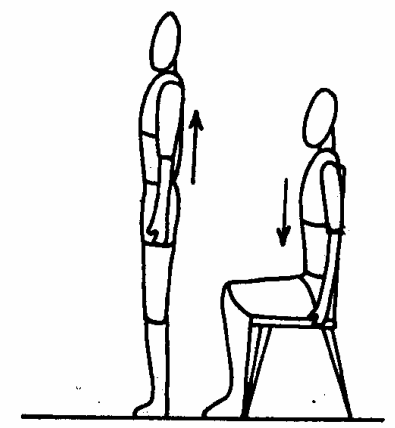

\section{Seated Hamstring Stretch}

- Sit down with one leg extended on a chair in front of you.

- Bend at the hip and lower your upper body towards your leg as far as you can.

- Do not lock your knees. You can place a rolled towel under your thigh to prevent this.

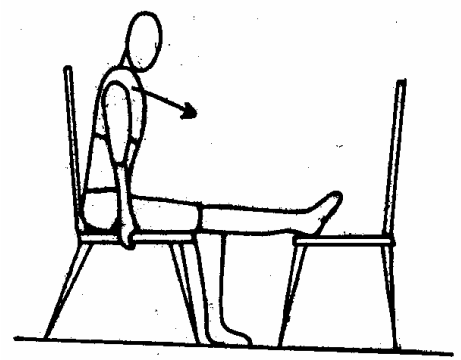

- Repeat with opposite leg.

- Hold for 15 to 30 seconds.

\section{Side-to-Side Stretch}

- Stand up straight.

- Place hands on hips.

- Slowly slide one hand down your side, towards your knee.

- Hold for 15 to 20 seconds.

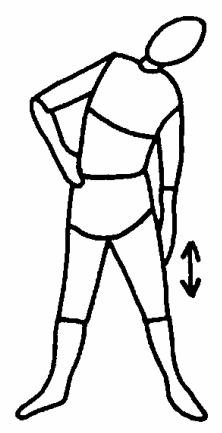

- Repeat on opposite side. 


\section{Lower Leg Stretch}

- Stand facing a wall with both hands against the wall, at chest level.

- Step back with one leg.

- Bend the front leg slightly. Be sure your knee does not go past your toes.

- Keep both heels on the ground.

- Hold this position for 15 to 30 seconds.

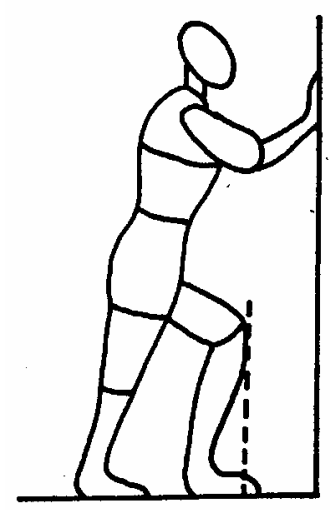

- Repeat on opposite leg.

\section{Head Lean}

- Stand or sit up straight.

- Slowly bring your right ear towards your right shoulder. Try not to raise your shoulder up towards your ear.

- Hold for a couple of seconds.

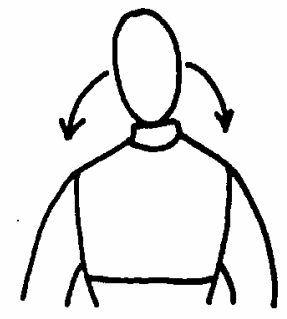

- Slowly bring your head back up to the starting position.

- Repeat this exercise 5 to 10 times alternating sides.

\section{Chin to Chest}

- Stand or sit up straight.

- Slowly bring your chin towards your chest as far as you can.

- Hold for a couple of seconds.

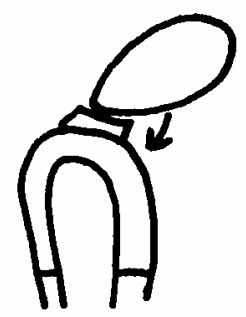

- Slowly bring your head back up to the starting position.

- Repeat 5 to 10 times. 